\title{
S-R and R-S acquisition as a function of meaningfulness
}

The acquisition of the components of paired-associate learning was examined in relation to the two-stage model of Underwood and Schulz and the symmetry model of Asch and Ebenholtz. Paired-associate learning was considered to include four components: forward association, backward association, stimulus learning, and response learning. Learning of pairedassociate material was hypothesized to be a function of the meaningfulness of the material. Components should be learned differently with high and low meaningful material. It was concluded that the Underwood and Schulz two-stage model of paired-associate learning is appropriate primarily for the learning of low meaningful material, whereas the symmetry model of Asch and Ebenholtz more accurately describes the learning of high meaningful material.

The most widely accepted paired-associate learning model is the two-stage, unidirectional model of Underwood \& Schulz (1960). In this model, learning of a palred-associate list consists only of response integration and differentiation and forward association learning.

In the two-stage model, little emphasis is placed on the role of stimuli in determining rate of learning, since it has been shown that variation in stimulus meaningfulness scarcely affects rate of learning, while variations in response meaningfulness have a considerable effect (Hunt, 1959; Kimble \& Dufort, 1955). Even less emphasis is placed on the role of backward associations. In fact, Goss (1963) has pointed out that Underwood and Schulz stressed response integration and response differentiation as their primary concern, and gave only brief attention to the other mechanisms involved in paired-assoclate learning.

In the associative symmetry model, Asch \& Ebenholtz (1962) maintained that when a forward association between two terms is formed, a backward association is simultaneously established with equal strength. A unidirectional or asymmetrical association between distinct terms, that is, $S$ to $R$ association only, cannot be established. The apparent predominance of forward associations in some studies has been attributed to differential availability of $S$ and $R$ terms.

The associative symmetry model also differs from the two-stage model with respect to the number of components of paired-associate learning. There are four possible components: $S-R$ association, R-S association, S learning, and $R$ learning. The symmetry model includes all four components, whereas the twostage model stresses only $S-R$ association and $R$ learning.

Statement of the Problem

The adequacy of the two models of paired-associate learning is tested in this study. The acquisition or learning of the four components of paired-associate learning is measured at various stages during the learning of the paired-associates. The experimental approach used differs in two ways from the usual method of measuring errors or trials to a criterion of learning. First, all the components of learning are measured. In addition, component learning is measured at various stages of learning.

The learning of paired-associate material is expected by the author to be a function of the meaningfulness of the learning materials. As meaningfulness varies, the components of the paired-associate task are learned differently. With high meaningful material, learning is symmetrical, with all components being learned simultaneously and to the same degree; with low meaningful material, an asymmetrical, two-stage model, in which response terms and S-R hook-up are learned, is expected to describe learning.

Method

The learning of a paired-associate task consisting of 12 pairs was investigated. Two levels of meaningfulness, represented by high and low meaningful paired assoclate lists, were used. The four components of learning consisted of the number of forward associations formed, the number of backward associations formed, the number of stimulus terms recalled, and the number of response terms recalled. Learning was measured at four stages of learning with 20 Ss tested at each stage. The four stages of learning were defined as correct anticipation of 3 to 4,6 to 7,9 to 10, and 12 terms, in a forward direction.

The learning materials consisted of two lists of 12 paired-associates derived from the lowest 24 and highest 24 items in Noble's (1952) list of dissyllables scaled for meaningfulness.

In the experimental task the stimulus term was presented for $2 \mathrm{sec}$, the paired stimulus and response terms were presented for $2 \mathrm{sec}$, followed by a 4-sec interval. After the criterion for a particular stage of learning was reached, the Ss were interrupted and tested for number of backward associations formed, number of response terms recalled, and number of stimulus terms recalled. Each response term was presented for $4 \mathrm{sec}$; the $S$ was instructed to state aloud the stimulus term with which he connected it. In the recall tests, the Ss were given $30 \mathrm{sec}$ in which to give orally the stimulus terms and $30 \mathrm{sec}$ in which to give the response terms. If, during the learning trials, a $S$ exceeded the number of correct anticipations for his assigned stage of learning, he was allowed 
to be placed in the next higher stage. The next $S$ to be tested was then assigned the former stage of learning. After completion of the testing, the individual was instructed to continue the task. Upon reaching the criterion of one perfect anticipation of the list, tests for backward associations and stimulus and response recall were again administered.

Resulfs and Discussion

It was predicted that significant main effects would be obtained for meaningfulness. This prediction was confirmed in all analyses, with more correct responses and fewer trials to criterion for the high meaningful groups $(p<.01)$.

The predicted significant main effects for stageby-stage performance for stages of learning were obtained $(p<.01)$. The number of correct responses increased across stages in a linear manner. When the number of correct responses at criterion were tested, groups tested at the various stages of learning were not different, indicating that testing of $\mathrm{Ss}^{\prime}$ learning at the various stages of learning produced no measurable differences in learning at criterion.

Relative to component learning, it was predicted that there would be more correct responses for $S$ and $R$ learning than for $R-S$ and $S-R$ learning. This prediction was not confirmed, either for stage-bystage or criterion performance. The greater amount of $R$ learning as compared with $S$ learning supports the two-stage model of paired-associate learning. The greater amount of $\mathrm{R}-\mathrm{S}$ learning as compared with $S$ and $R$ learning was attributed to the difference in obtaining measurements of these two components. Measurements of $S$ and $R$ learning were obtained by a free recall technique. R-S learning measurements were obtained by a cued technique in which the Ss were given the response term and asked to supply the correct stimulus term. Cued measurements would be expected to surpass free recall measurements.

As predicted, the interaction between meaningfulness and components of learning was significant $(\mathrm{p}<$ .01). For stage-by-stage acquisition, the significant interaction arose from a greater number of $R-S$ responses over $R$ and $S$ responses, for high meaningfulness. R-S acquisition did not differ from $R$ and $S$ acquisition for low meaningfulness. An increase in the number of $\mathrm{R}-\mathrm{S}$ associations, therefore, is a principal effect of high meaningfulness. Similarly, for number of correct responses, the high meaningful group gave a disproportionate number of correct backward association responses at criterion.

The interaction between meaningfulness and stages of learning was not significant. Similar rates of learning were demonstrated for high and low meaningfulness.

When differences between the number of forward and backward associations for meaningfulness and the four stages of learning were tested, a predominance of backward associations for the high meaningful group at the early stages of learning was noted. In the later stages of learning, the number of forward and backward associations approached equality. Forward and backward associations for the low meaningful group started out approximately equal; however, forward associations increased across stages and predominated at criterion. Backward associations thus occur primarily with high meaningful material.

These findings illustrate the effect of meaningfulness on component learning. It may be concluded that the amount of paired-associate material learned is a function of the meaningfulness of the learning materials. Difficulty, types of associations formed, and the rate at which the types of associations are formed vary with meaningfulness. The findings lead to the conclusion that the two-stage model is appropriate primarily for the learning of low meaningful materials, whereas the symmetry model more accurately describes the learning of high meaningful materials.

\section{References}

ASCH, S. E., \& EBENHOLTZ, S. M. The principle of associative symmetry. Proc. Amer. Phil, Soc., 1962, 106, 135-163.

ASCH, S. E., \& LINDER, M. A note on "strength of association." $J$. Psychol, 1963, 55, 199-209.

GOSS, A. E. Comments on Professor Noble's paper. In C. N. Cofer \& B. S. Musgrave (Eds.), Verbal behavior and learning: problems and processes. New York: McGraw-Hill, 1963.

HUNT, R. G. Meaningfulness and articulation of stimulus and response in paired-associate learning and stimulus recall. J. exp. Psychol., 1959, 57, 262-267.

KIMBLE, G. A., \& DUFORT, R. H. Meaningfulness and isolation as factors in verbal learning. J. exp. Psychol, 1955, 50, 361-368.

NOBLE, C. E. An analysis of meaning. Psychol Rev., 1952, 59, 421-430.

UNDERWOOD, B. J., \& SCHULZ, R. W. Meaningfulness and verbal learning. Philadelphia: Lippincott, 1960. 